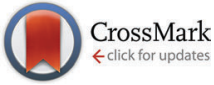

Cite this: Phys. Chem. Chem. Phys., $2016,18,7278$

Received 14th December 2015, Accepted 9th February 2016

DOI: $10.1039 / c 5 c p 07026 k$

www.rsc.org/pccp

\section{Stabilization of DNA liquid crystals on doping with gold nanorods $\dagger$}

\author{
Katarzyna Brach, Katarzyna Matczyszyn, * Joanna Olesiak-Banska, Marta Gordel \\ and Marek Samoc
}

\begin{abstract}
We report on the impact of doping with gold nanorods (NRs) on the formation and stability of DNA liquid crystals (LCS). Cetyl trimethylammonium (CTAB)-stabilized gold NRs were synthesized using the wet chemistry method. Different textures of cholesteric and columnar mesophases, as well as phase transitions, were observed using a polarized light microscope. It was found that liquid crystalline phases formed in the samples were qualitatively the same and the phase appearance sequence was preserved in the samples regardless of the doping. We show that depending on the concentration of gold NRs present in the phase, nanoparticle-doped cholesteric and columnar hexagonal phases existed in wider temperature ranges compared to pure DNA LCs. The potential applications of these liquid crystal-nanoparticle hybrid systems may include the fabrication of new optoelectronic devices and sensors.
\end{abstract}

\section{Introduction}

Recently, the topic of nanoparticles dispersed in liquid crystalline matrices has been gaining considerable attention. Combining the unique properties of nanoparticles with the ability of LCs to self-assemble and their mobility provides new opportunities for designing novel advanced functional materials, which could be used in the fields of electronics or optoelectronics. ${ }^{1-3}$ Most of the liquid crystalline-nanoparticles hybrid systems described to date involved nematics, ${ }^{2-4}$ blue phases ${ }^{5,6}$ or lamellar ${ }^{7}$ phases doped with different types of nanostructures, including gold, ${ }^{7}$ semiconductor $^{1,5}$ or ferroelectric ${ }^{2}$ nanoparticles. The introduction of nanoparticles into LCs provides some crucial and desirable changes in LC characteristics, such as increase of the thermal stability, ${ }^{5,6}$ decrease of the threshold voltage for the Freedericksz transition $^{8}$ or increase of the dielectric anisotropy. ${ }^{9}$

There are only few papers concerning the topic of DNA LCs doped with gold nanoparticles. ${ }^{10-14}$ It is still quite an unexplored area of research, where so far De Sio et al. proved that DNA LCs were able to organize gold NRs within DNA LCs deposited on a glass substrate by drop casting and allowed to dry, ${ }^{10}$ and Yevdokimov et al. showed the formation of linear clusters of small gold nanopartciles (with diameter around $2 \mathrm{~nm}$ ) in a cholesteric liquid crystalline dispersion of DNA. ${ }^{14}$

However, the properties of a composite material consisting of gold NRs with strong plasmon resonances dispersed in DNA

Advanced Materials Engineering and Modelling Group, Wroclaw University of Technology, Wybrzeze Wyspianskiego 27, 50-370 Wroclaw, Poland.

E-mail: katarzyna.matczyszyn@pwr.edu.pl

$\dagger$ Electronic supplementary information (ESI) available. See DOI: 10.1039/c5cp07026k lyotropic LCs prepared in closed glass cells, where the type of observed phases and molecular organization are different compared to previously mentioned DNA LCs, ${ }^{10-14}$ have not been studied in detail yet. Lacaze et al. showed that it is possible to order small nanoparticles using smectic $\mathrm{LCs}^{15}$ and our intent was to check this ability for DNA LCs, but it is necessary to evaluate the basic properties of DNA LC-nanoparticle hybrid systems first. The advantage of using DNA as a material for nanoparticle ordering or trapping is that DNA may serve as a perfect self-organized flexible matrix or scaffolding, which is also environmentally friendly and biodegradable. ${ }^{16}$ The synergy between the properties of a LC and nanoparticles may be highly beneficial for obtaining advanced functional materials with new and/or improved properties. Dispersing nanoparticles in LCs offers a simple method for tuning the physical properties of LCs without additional chemical modifications of mesogens, as well as provides an uncomplicated approach for ordering nanoparticles in two- or three-dimensional structures. The research in the field of liquid crystalline nanocomposite materials can contribute to the development of a novel class of soft biomaterials with many possible applications in the field of photonic and electronic devices or metamaterials.

In this report, we investigate the properties of gold NRs-doped DNA cholesteric and columnar phases. The method of dispersing gold NRs in the liquid crystalline matrix is described and the influence of nanostructures on the LC phase formation, texture appearance and thermal stability is presented. We compare pure DNA LCs and those doped with various amounts of gold NRs and nanoparticle stabilizing effect on the LCs. First, we evaluate the phase formation sequence and the textures observed under a polarized light microscope. Next, we check the phase transition 
temperatures in order to determine the effect of the NR addition on the thermal stabilization of LC phases. We propose possible explanations for the differences found between the prepared systems. Finally, we present the conclusions of our work.

\section{Materials and methods}

\section{Chemicals}

Deoxyribonucleic acid sodium salt from salmon testes, $\mathrm{HAuCl}_{4}$. $3 \mathrm{H}_{2} \mathrm{O}(99.9 \%), \mathrm{NaBH}_{4}(99 \%)$, ascorbic acid (AA) $(99+\%), \mathrm{CTAB}$ $(99 \%)$ and $\mathrm{AgNO}_{3}(99+\%)$ were purchased from Sigma Aldrich. All chemicals were used as received except when mentioned specifically. All solutions were prepared using Milli-Q water of resistivity not less than $18.2 \mathrm{M} \Omega \mathrm{cm}$.

\section{Sample preparation}

Gold NRs were synthesized using a seed-mediated growth approach. ${ }^{17}$ Briefly, $3.5 \mathrm{~nm}$ gold seeds were prepared by adding gold salt solution to a reducing agent, freshly prepared ice-cold borohydride solution and using CTAB as a capping agent. The next step consisted of the growth of NRs in silver nitrate solution, influencing rod-shaped nanoparticle formation, in the presence of $\mathrm{AA}$ and CTAB micelles. In order to separate the NRs from nanospheres the sample was centrifuged at $14000 \mathrm{rpm}$.

The preparation of DNA LCs doped with gold NRs was preceded by DNA sonication in an ultrasonic homogenizer (Autotune Series High Intensity Ultrasonic Processor), which resulted in more homogenously sized DNA molecules (approximately 250-1000 bp). Highly concentrated DNA solutions $\left(C_{\mathrm{DNA}}=60 \mathrm{mg} \mathrm{mL}{ }^{-1}\right)$ were prepared and doped with various amounts of gold NRs $\left(C_{\mathrm{NR}}=0.036 \mathrm{mg} \mathrm{mL}^{-1}\right.$ or $\left.C_{\mathrm{NR}}=0.278 \mathrm{mg} \mathrm{mL}^{-1}\right)$ or with various amounts of СТAB ( $C_{\mathrm{CTAB}}$ varied from $0.01 \mathrm{mg} \mathrm{mL}^{-1}$ to $1 \mathrm{mg} \mathrm{mL}^{-1}$ ). Finally, the DNA solutions were placed between clean glass slides and coverslips and sealed with the DPX mountant for histology (Fluka). The LC samples were stored for several weeks at $4{ }^{\circ} \mathrm{C}$.

\section{Instrumentation}

A FEI Tecnai G2 20 X-TWIN transmission electron microscope was used to characterize the size and shape distributions of the gold nanoparticles. The ultraviolet-visible (UV-Vis) absorption spectra were obtained at room temperature using a Thermo Spectronic Unicam UV 300 spectrophotometer. The textures of DNA liquid crystalline phases, as well as the phase transitions as a function of temperature were observed under an Olympus 60BX polarized light microscope equipped with a hot-stage and a camera. The accurate values of the liquid crystalline to isotropic transition temperatures were determined by calorimetry using a Perkin-Elmer DSC-7 differential scanning calorimeter.

\section{Results and discussion}

\section{Nanoparticle characterization}

Gold NRs synthesized by the wet chemistry method exhibited two different absorption bands arising from a transverse surface plasmon resonance observed at $520 \mathrm{~nm}$ and a longitudinal
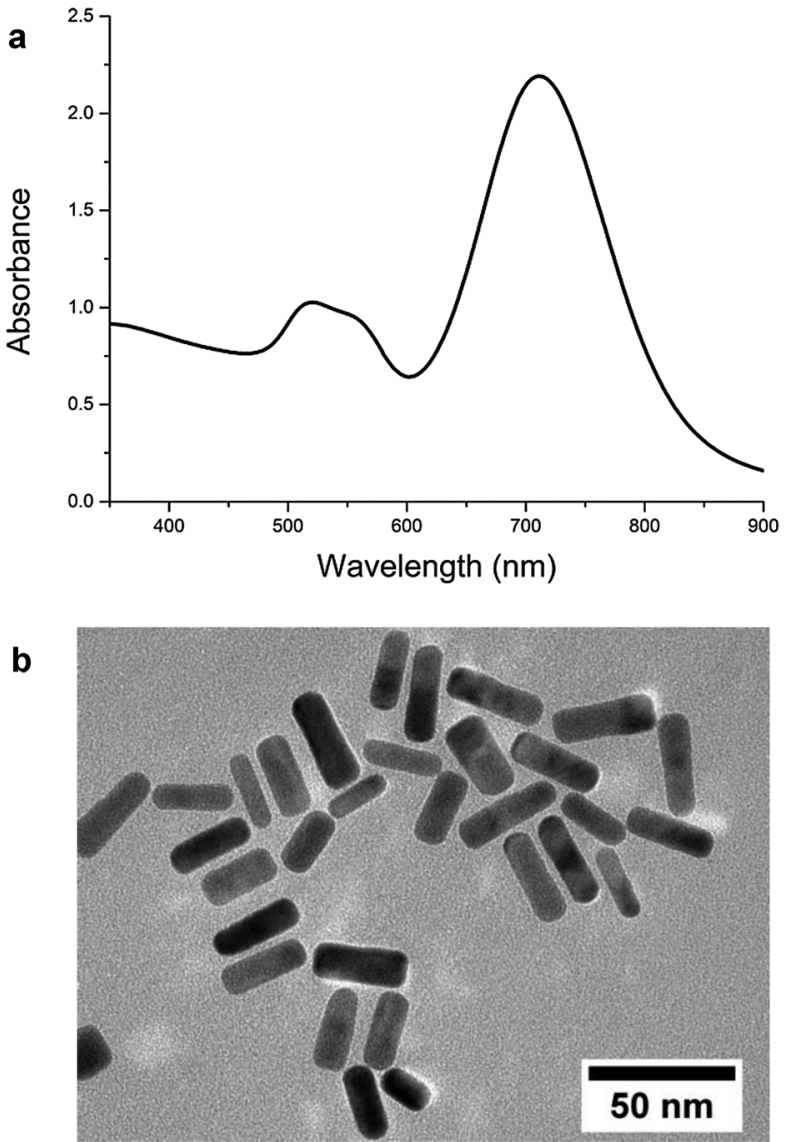

Fig. 1 (a) Absorption spectrum of gold NRs. (b) TEM image of gold NRs.

surface plasmon resonance observed at $715 \mathrm{~nm}$ (Fig. 1a and Fig. S1, ESI †). Transmission electron microscope (TEM) observations provided useful information about morphology of nanoparticles obtained after the synthesis (Fig. 1b). The average length and width of the NRs were $35 \mathrm{~nm}$ and $10 \mathrm{~nm}$, respectively.

\section{DNA liquid crystalline phases}

DNA molecules at higher concentrations in aqueous solution tend to self-organize into various liquid crystalline phases. ${ }^{18-21}$ Their formation and properties strongly depend on the properties of DNA solution and the presence of ions or dopants. Within a few days after liquid crystalline cell preparation, the isotropic solution changes itself into a cholesteric phase, which subsequently transforms into a columnar hexagonal phase. The order of phase formation was consistent with previous studies ${ }^{19}$ and was preserved in all the prepared LC samples, irrespective of the LC doping.

\section{Cholesteric phases}

Due to their chirality, double helices of DNA may self-assemble into cholesteric phases. This mesophase is also called a chiral nematic phase. The cholesteric LC phase is composed of layers with nematic ordering, which are slightly rotated with respect to each other. The axis of this rotation is normal to the director. An important parameter characterizing the cholesteric mesophase is the pitch $P$, which defines the distance of a full turn of the 
helical superstructure of molecular layers. Typical textures which are observed for DNA cholesterics placed between crossed polarizers under an optical microscope are oily streaks, Grandjean and fingerprint textures. ${ }^{22}$

It is very common to observe cholesteric spherulites during the initial phase of cholesteric mesophase formation. Spherical droplets of the cholesteric phase nucleated in the isotropic phase in pure and NRs-doped LC cells after a few days of incubation at $4{ }^{\circ} \mathrm{C}$. We noticed that, depending on the concentration of NRs in the LC phase, different sizes and orientations of cholesteric layers of spherulites, with respect to the preparation plane, were obtained (Fig. 2). Fig. 2a presents cholesteric droplets formed in the case of pure DNA LCs. The size of these spherulites varied from 10 to $100 \mu \mathrm{m}$ and the cholesteric layers were lying parallel to the interface. Chiral nematic droplets obtained for a LC doped with gold NRs at the concentration of $C_{\mathrm{NR}}=0.036 \mathrm{mg} \mathrm{mL}^{-1}$ were significantly smaller, with the size distribution between 7 and $40 \mu \mathrm{m}$. The cholesteric layers of spherulites were aligned either parallel or normal to the interface (Fig. 2b). The smallest cholesteric droplets were observed in a liquid crystalline cell containing the highest amount of NRs. Their size was between 8 and $27 \mu \mathrm{m}$ and the cholesteric layers were normal with respect to the preparation plate (Fig. 2c).

The size and shape of cholesteric spherulites depend on many parameters, but mainly on equilibrium between bulk free energy and surface free energy. ${ }^{23}$ It was found that the presence of nanoparticles in a liquid may lead to an increase of surface tension and surface energy. ${ }^{24,25}$ This phenomenon is responsible for the growing contribution of surface free energy in the total free energy of a cholesteric droplet, which can consequently lead to the reduced size of spherulites, as it was observed in DNApolymer mixtures. ${ }^{23,26}$ The introduction of gold NRs impacted the cholesteric layer orientation. Vertical disclination lines of spherulites observed in a sample without NRs were not observed in a sample with the highest concentration of NRs. In contrast, cholesteric layers aligned normal to the interfaces with glass plates. The exact impact of gold NR addition on the size and shape of spherulites, especially their cholesteric layer orientation is under detailed study in our laboratory.

Domains of cholesteric phases were observed not only in a control sample (Fig. 3a), but also in both types of doped DNA LCs (Fig. 3b-d). The size and shape of liquid crystalline domains were found to be similar between the samples. A variety of defects in the form of singular points, lines and walls are commonly found in LCs. In the case of DNA cholesterics, the most common ones are $\tau$ and $\lambda$ disclinations, which are connected with the change in the director orientation, and dislocations, which are associated with the addition or removal of at least one layer in the cholesteric phase. ${ }^{27}$ Numerous defects, disclinations and dislocations, were present in all observed cholesteric phases regardless of the presence of gold NRs or CTAB in a liquid crystalline matrix. We did not notice any significant relationship between the amount of the dopant present in the phase and the number of phase defects.

The helical pitch was measured directly from the photographs of fingerprint textures. We observed that the difference between cholesteric pitch values is dependent on the presence of dopants in the phase. Addition of gold NRs caused a slight increase of $P$ values in both cases. For pure DNA LCs the average value of $P$ was $5.11 \mu \mathrm{m}$, whereas for LCs doped with NRs at the concentration of $C_{\mathrm{NR}}=0.036 \mathrm{mg} \mathrm{mL}^{-1}$ and $C_{\mathrm{NR}}=0.278 \mathrm{mg} \mathrm{mL}^{-1}$ it was $5.30 \mu \mathrm{m}$ and $5.18 \mu \mathrm{m}$, respectively. Additionally, the more NRs were present in the LCs, the smaller distribution of data around the mean value of $P$ was obtained. Population standard deviation values for the control LC and LCs with increasing amounts of gold NRs were as follows: $1.21,0.79$ and $0.62 \mu \mathrm{m}$. In the case of CTAB-doped LCs, an increase of cholesteric $P$ was noticed as well. Comparing these doped LCs with pure DNA LCs, we observed that the helical $P$ values increased by 0.3 to $1.5 \mu \mathrm{m}$. We did not observe any significant relationship between the increasing CTAB concentration and the values of $P$ found in the corresponding CTAB-doped LCs or distributions of data around the mean value of $P$. According to the literature, addition of various dopants modifies the cholesteric $P$ of LC DNA. ${ }^{28}$ One of the most crucial parameters influencing the helical $P$ value is charge distribution on DNA chains. ${ }^{29}$ Thus, the introduction of gold NRs into DNA LCs might have impacted the charge distribution along DNA molecules by electrostatic interactions between CTAB present on the surface of NRs and negatively charged DNA. ${ }^{30}$ CTAB belongs to the group of cationic surfactants, which may cause DNA condensation. ${ }^{31}$ Consequently, the addition of CTAB or CTAB-stabilized gold NRs to the host LCs induced modifications in intermolecular distances. In this case, the increase of $P$ value can also be correlated with the
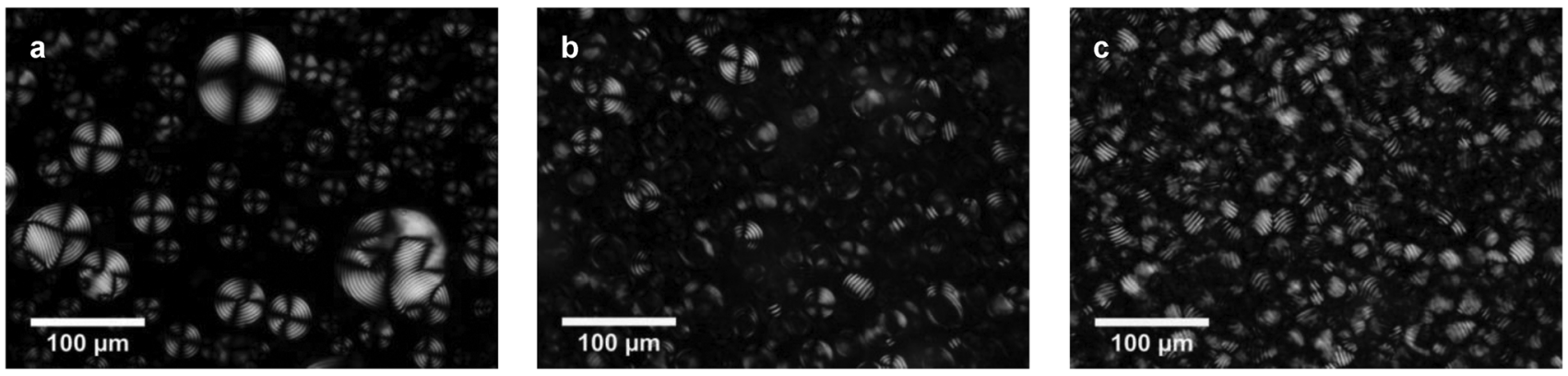

Fig. 2 Cholesteric droplets formed after 4 days of preparation in the case of (a) pure DNA LC; (b) NRs-doped DNA LC, $C_{\mathrm{NR}}=0.036 \mathrm{mg} \mathrm{mL}^{-1}$; and (c) NRs-doped DNA LC, $C_{\mathrm{NR}}=0.278 \mathrm{mg} \mathrm{mL}^{-1}$. 

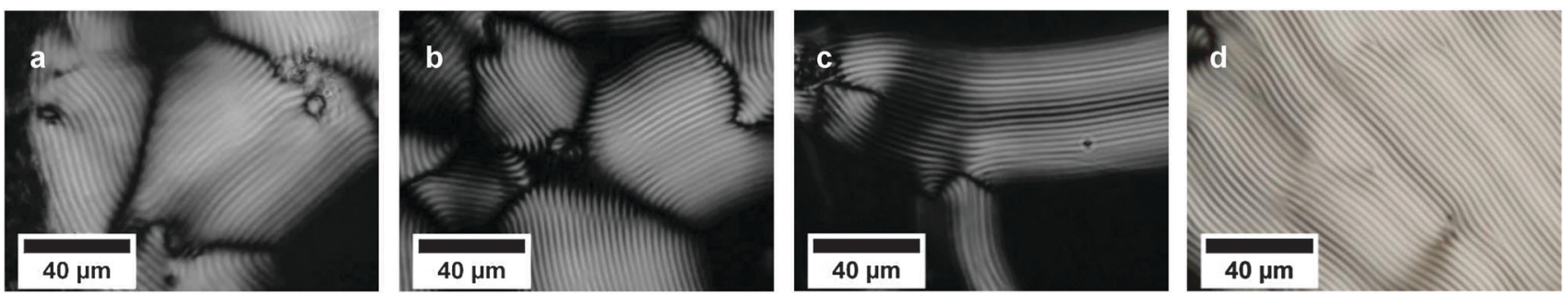

Fig. 3 Fingerprint textures of cholesteric DNA LCs observed 29 days after the preparation: (a) pure DNA LC; (b) NRs-doped DNA LC, $C_{N R}=0.036 \mathrm{mg} \mathrm{mL}^{-1}$; (c) NRs-doped DNA LC, $C_{\mathrm{NR}}=0.278 \mathrm{mg} \mathrm{mL}^{-1}$; and (d) CTAB-doped DNA LC, $C_{\mathrm{CTAB}}=1 \mathrm{mg} \mathrm{mL}^{-1}$.

alteration in the distance between DNA molecules in the adjacent cholesteric layers.

\section{Columnar hexagonal phases}

Alignment of mesogenic molecules in columnar hexagonal phases is completely different from molecular organization in cholesteric LCs, which manifests as an observation of other types of liquid crystalline textures, such as fan-shaped or undulating textures. In the case of DNA LCs, the change from a cholesteric to a columnar hexagonal mesophase is a result of slow water evaporation, which causes an increase of DNA concentration. In this phase, helices align parallel to each other in a two-dimensional hexagonal lattice. ${ }^{19}$

Similarly to the cholesteric phase, a columnar hexagonal phase was found in all prepared samples irrespective of the LC doping (Fig. 4). The presence of gold NRs in the phase did not influence the columnar phase formation, and the size and textures of LC domains remained similar. NRs or CTAB addition did not impact the mesophase order formation. Typical columnar hexagonal phase defects, such as $+\pi$ and $-\pi$ disclination lines and walls separating domains of different molecular arrangements, were observed in LC cells. The same conclusions concerning the formation and appearance of a columnar hexagonal phase with a periodic zigzag pattern in dried droplets of DNA solution doped with gold NRs were previously drawn by our research group. ${ }^{11}$

\section{Thermal stability of DNA LCs}

Polarized light microscopy (PLM) is one of the most common tools used for the investigation of liquid crystalline phases, which allows differentiation between various LC textures and also the study and observation of phase transitions as a function of temperature. Transformation between different mesophases is the result of the order parameter change. Thus, two types of phase transitions can be distinguished, from an ordered to a less ordered phase and vice versa, depending on an increase or a decrease of the temperature, respectively. ${ }^{32}$ We observed phase transitions during cholesteric and columnar hexagonal phase heating. To prevent water boiling, the sample heating was carried out up to $93{ }^{\circ} \mathrm{C}$.

For cholesteric to isotropic phase transitions, we found that the more NRs were used to dope the phase, the higher temperature of the phase transition was obtained. For the control sample the clearing temperature was $57{ }^{\circ} \mathrm{C}$, whereas for the LCs doped with NRs at the concentration of $C_{\mathrm{NR}}=0.036 \mathrm{mg} \mathrm{mL}^{-1}$ it was $62.5^{\circ} \mathrm{C}$ and at $C_{\mathrm{NR}}=0.278 \mathrm{mg} \mathrm{mL}^{-1}$ it was $69.5^{\circ} \mathrm{C}$. For CTAB-doped LCs, we observed two opposite trends determined by the cationic surfactant concentration. For the growing concentration of CTAB in liquid crystalline cells (up to $C_{\mathrm{CTAB}}=0.036 \mathrm{mg} \mathrm{mL}^{-1}$ ) maximum $16{ }^{\circ} \mathrm{C}$ increase of the clearing temperature value was found compared to pure DNA LCs. After exceeding $C_{\mathrm{CTAB}}=$ $0.036 \mathrm{mg} \mathrm{mL}{ }^{-1}$, clearing temperatures for the corresponding CTAB-doped LCs decreased up to $10{ }^{\circ} \mathrm{C}$. A calorimetric study of CTAB-DNA complexes by Marchetti et al. showed that in the presence of different CTAB concentrations, the surfactant-saturated DNA exhibited higher thermal stability over $100{ }^{\circ} \mathrm{C} .{ }^{33}$ However, the difference between these results and ours might be the consequence of different methods of sample preparation and investigation.

We monitored the changes in the cholesteric $P$ value during liquid crystalline phase heating. The same relationship between the $P$ value and the increase of temperature was found in all investigated samples. Initially, we noticed a decrease of $P$, and then, after reaching the minimum $P$ value and before the transformation into the isotropic phase, the $P$ value increased again. For many thermotropic cholesterics, $P$ decreases with increasing temperature, but for lyotropics this dependence is
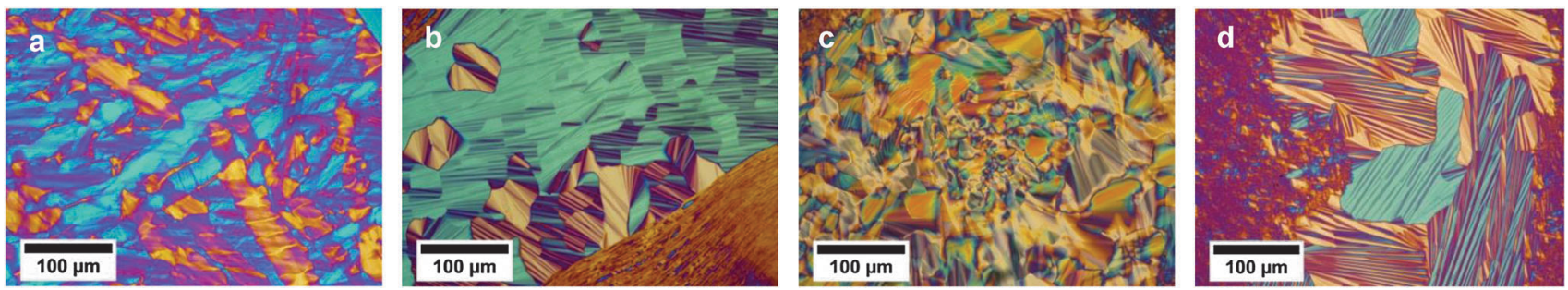

Fig. 4 Columnar hexagonal phase in DNA LCs: (a) pure DNA LC; (b) NRs-doped DNA LC, $C_{N R}=0.036 \mathrm{mg} \mathrm{mL}^{-1}$; (c) NRs-doped DNA LC, $C_{\mathrm{NR}}=0.278 \mathrm{mg} \mathrm{mL}^{-1}$; and (d) CTAB-doped DNA LC, $C_{C T A B}=1 \mathrm{mg} \mathrm{mL}^{-1}$. Photos were taken with a full wave retardation plate. 

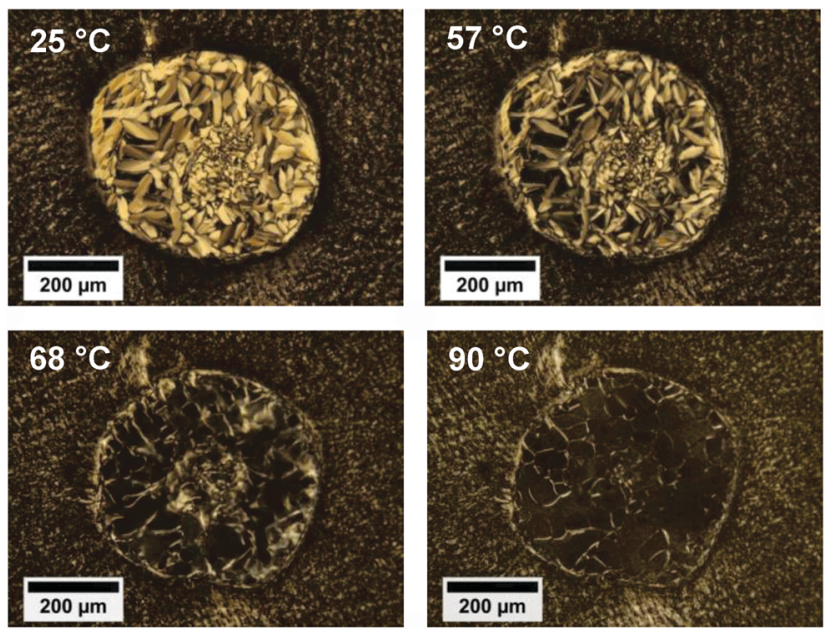

Fig. 5 Columnar hexagonal to cholesteric phase transition in a NRs-doped DNA LC cell $\left(C_{\mathrm{NR}}=0.278 \mathrm{mg} \mathrm{mL}^{-1}\right)$.

more complex. The initial decrease of $P$ and the subsequent increase may be the result of a competition between steric and dispersive chiral interactions and stronger thermal fluctuations, ${ }^{34}$ which finally led to a rapid pitch growth just before the phase transition.

Observations of columnar to isotropic phase transitions led to similar conclusions about the dependence of the clearing temperature on the gold NR presence in the phase. For the pure DNA LC and the LC doped with NRs at the concentration of $C_{\mathrm{NR}}=0.036 \mathrm{mg} \mathrm{mL}^{-1}$, the phase transition temperatures were $72.5{ }^{\circ} \mathrm{C}$ and $79.3{ }^{\circ} \mathrm{C}$, respectively. In the case of CTAB-doped LCs, the clearing temperatures increased by 5 to $20{ }^{\circ} \mathrm{C}$. The cholesteric-isotropic phase transition temperatures were lower than those of columnar-isotropic phase transitions. This might be explained by the difference in the degree of molecular order and orientation within the phases, where for the columnar hexagonal phase a higher degree of ordering is found. Interestingly, in the case of the LC doped with NRs at the concentration of $C_{\mathrm{NR}}=0.278 \mathrm{mg} \mathrm{mL}^{-1}$, we did not observe any phase transition upon heating up to $93{ }^{\circ} \mathrm{C}$. We conducted the columnar phase heating for the LC cell containing the highest amount of NRs again, and similarly we did not notice a columnar-isotropic phase transition, but at $57{ }^{\circ} \mathrm{C}$ a columnar to cholesteric phase transition, which was not observed in other LC samples, had begun and continued up to $93{ }^{\circ} \mathrm{C}$ (Fig. 5). The polarized light microscopic observations of phase transitions are summarized in Table 1.

Table 1 Phase transition temperatures determined from PLM observations

\begin{tabular}{lllll}
\hline & \multicolumn{3}{c}{ Phase transition temperature $\left({ }^{\circ} \mathrm{C}\right)$} \\
\cline { 2 - 4 } & $\begin{array}{l}\text { Control } C_{\mathrm{CTAB}}=0.01 \\
\text { sample to } 1 \mathrm{mg} \mathrm{mL} \mathrm{mL}^{-1}\end{array} \mathrm{mg} \mathrm{mL}_{\mathrm{NR}}=0.036$ & $\begin{array}{l}C_{\mathrm{NR}}=0.278 \\
\mathrm{mg} \mathrm{mL}\end{array}$ \\
\hline $\begin{array}{l}\text { Pholesteric to } \\
\text { isotropic }\end{array}$ & 57.0 & $47.0-73.0$ & 62.5 & 69.5 \\
$\begin{array}{l}\text { Columnar hexagonal } \\
\text { to isotropic }\end{array}$ & 72.5 & $77.5-92.5$ & 79.3 & Not observed \\
& & & &
\end{tabular}

\section{Acknowledgements}

We gratefully acknowledge the funding for this research from an NCN OPUS DEC-2013/09/B/ST5/03417 grant. This work was also supported by a statutory activity subsidy from the Polish Ministry of Science and Higher Education for the Faculty of Chemistry of Wroclaw University of Technology. 


\section{References}

1 S. Kumar, NPG Asia Mater., 2014, 6, 1-13.

2 R. Basu, Phys. Rev. E: Stat., Nonlinear, Soft Matter Phys., 2014, 89, 022508.

3 Y. Zhang, Q. Liu, H. Mundoor, Y. Yuan and I. I. Smalyukh, ACS Nano, 2015, 9, 3097-3108.

4 H. Duran, B. Gazdecki, A. Yamashita and T. Kyu, Liq. Cryst., 2005, 32, 815-821.

5 L. Wang, W. L. He, X. Xiao, F. U. Meng, Y. Zhang, P. Y. Yang, L. P. Wang, J. M. Xiao, H. Yang and Y. F. Lu, Small, 2012, 8, 2189-2193.

6 A. Sharma, M. Worden and T. Hegmann, Ferroelectrics, 2012, 431, 154-163.

7 Z. M. Sui, X. Chen, L. Y. Wang, L. M. Xu and C. J. Yang, Acta Phys.-Chim. Sin., 2006, 22, 737-743.

8 F. Haraguchi, K. I. Inoue, N. Toshima, S. Kobayashi and K. Takatoh, Jpn. J. Appl. Phys., Part 2, 2007, 46, L796-L797.

9 J. Mirzaei, M. Urbanski, H. S. Kitzerow and T. Hegmann, Philos. Trans. R. Soc., A, 2013, 371, 20120256.

10 L. De Sio, F. Annesi, T. Placido, R. Comparelli, V. Bruno, A. Pane, G. Palermo, M. L. Curri, C. Umeton and R. Bartolino, J. Opt., 2015, 17, 025001.

11 J. Olesiak-Banska, M. Gordel, K. Matczyszyn, V. Shynkar, J. Zyss and M. Samoc, Nanoscale, 2013, 5, 10975-10981.

12 Y. M. Yevdokimov and O. N. Kompanets, Phys.-Usp., 2014, 57, 615-621.

13 S. G. Skuridin, V. I. Salyanov, V. I. Popenko, E. V. Shtykova, E. S. Lisitsyna, V. A. Dubinskaya, V. A. Bykov and Y. M. Yevdokimov, Pharm. Chem. J., 2013, 47, 71-79.

14 Y. M. Yevdokimov, E. V. Shtykova, V. I. Salyanov and S. G. Skuridin, Biophysics, 2013, 52, 148-156.

15 D. Coursault, J. Grand, B. Zappone, H. Ayeb, G. Levi, N. Felidj and E. Lacaze, Adv. Mater., 2012, 24, 1461-1465.
16 K. Matczyszyn and J. Olesiak-Banska, J. Nanophotonics, 2012, 6, 064505.

17 T. K. Sau and C. J. Murphy, Langmuir, 2004, 20, 6414-6420.

18 J. Olesiak, K. Matczyszyn, H. Mojzisova, M. Zielinski, D. Chauvat and J. Zyss, Mater. Sci.-Pol., 2009, 27, 813-823.

19 F. Livolant and A. Leforestier, Prog. Polym. Sci., 1996, 21, 1115-1164.

20 A. Leforestier and F. Livolant, Liq. Cryst., 1994, 17, 651-658. 21 F. Livolant, J. Phys., 1987, 48, 1051-1066.

22 T. Bellini, R. Cerbino and G. Zanchetta, in Liq. Cryst., ed. C. Tschierske, Springer, Berlin Heidelberg, 2012, vol. 318, ch. 230, pp. 225-279.

23 A. Goldar, H. Thomson and J. M. Seddon, J. Phys.: Condens. Matter, 2008, 20, 035102.

24 C. T. Campbell, S. C. Parker and D. E. Starr, Science, 2002, 298, 811-814.

25 J. Drelich, J. Nanomater. Mol. Nanotechnol., 2013, 2, 1.

26 J. Ubbink and T. Odijk, Biophys. J., 1995, 68, 54-61.

27 A. Leforestier and F. Livolant, Biophys. J., 1993, 65, 56-72.

28 J. Olesiak-Banska, H. Mojzisova, D. Chauvat, M. Zielinski, K. Matczyszyn, P. Tauc and J. Zyss, Biopolymers, 2011, 95, 365-375.

29 A. A. Kornyshev, S. Leikin and S. V. Malinin, Eur. Phys. J. E: Soft Matter Biol. Phys., 2002, 7, 83-93.

30 S. Husale, W. Grange, M. Karle, S. Burgi and M. Hegner, Nucleic Acids Res., 2008, 36, 1443-1449.

31 R. Dias, S. Mel'nikov, B. Lindman and M. G. Miguel, Langmuir, 2000, 16, 9577-9583.

32 S. Singh, Phys. Rep., 2000, 324, 108-269.

33 S. Marchetti, G. Onori and C. Cametti, J. Phys. Chem. B, 2006, 110, 24761-24765.

34 M. Pape and K. Hiltrop, Mol. Cryst. Liq. Cryst. Sci. Technol., Sect. A, 1997, 307, 155-173. 